\title{
Lodging resistance and yield potential of winter wheat: effect of planting density and genotype
}

\author{
Yonggui XIAO', Jianjun LIU ${ }^{2}$, Haosheng LI $^{2}$, Xinyou CAO ${ }^{2}$, Xianchun XIA ${ }^{1}$, Zhonghu HE (凶) $)^{1,3}$ \\ 1 Institute of Crop Science, National Wheat Improvement Center, Chinese Academy of Agricultural Sciences (CAAS), Beijing 100081, China \\ 2 Crop Research Institute, Shandong Academy of Agricultural Sciences, Jinan 250100, China \\ 3 International Maize and Wheat Improvement Center (CIMMYT) China Office, c/o CAAS, Beijing 100081, China
}

\begin{abstract}
Improved lodging resistance is important for achieving high yield in irrigated environments. This study was conducted to determine genotypic variation in lodging resistance and related morphological traits among winter wheat cultivars planted at two densities, and to identify key traits associated with lodging resistance. Lodging performance of 28 genotypes, including 24 released cultivars and four advanced lines, was evaluated at 250 plants per square meter and 500 plants per square meter in Shandong province during the 2008-2009 and 2009-2010 crop seasons. At the higher density, the average grain yield was $2.6 \%$ higher, even though lodging score rose by as much as $136 \%$. The higher planting density increased lodging through increased leaf area index (LAI), plant height, center of gravity and length of basal internodes, and reduced grain weight per spike and diameter of the lower two stem internodes. LAI, center of gravity and diameter of first internodes, as the important indicators for lodging resistance, were significantly correlated with lodging score, with $R=0.62,0.59$ and $-0.52(P<0.01)$, respectively. Plant pushing resistance was significantly associated with diameter and length of the first internodes ( $R=0.71-0.77, P<0.01$ ), indicating it could be used to assess the strength of the lower stem. Higher planting density could be used to select genotypes with lodging resistance in irrigated environments. Cultivars carrying high plant density tolerance and high yield potential, such as Jimai 22 and Liangxing 66, were recommended as leading cultivars for production as well as elite crossing parents for further increasing yield potential in the Yellow and Huai Valleys Winter Wheat Zone in China.
\end{abstract}

Keywords common wheat, yield potential, lodging performance, pushing resistance, leaf area index

Received April 29, 2015; accepted June 1, 2015

Correspondence: zhhecaas@163.com

\section{Introduction}

Lodging arising from permanent displacement of plant shoots from upright stature is a complex phenomenon that interferes with photosynthate transportation and dry matter accumulation. It reduces photosynthetic potential, provides a favorable environment for fungal growth and leaf disease development, and thus increases agronomic costs and causes yield loss ${ }^{[1]}$. It can reduce grain yield by up to $80 \%$ and significantly decrease bread-making quality ${ }^{[2,3]}$. In China, unlike the $\mathrm{UK}^{[4]}$, plant growth regulators are not commonly used to reduce plant height in high yielding environments, thus lodging is the most important constraint to achieving high yield in the wheat/maize rotation system in the Yellow and Huai Valleys Winter Wheat Zone (YHVWWZ), where $70 \%$ of the national wheat is produced $^{[5]}$. Shorter cultivars with better lodging resistance, developed by introducing semi-dwarfing genes such as Rht-B1b (Rht1) and Rht-D1b (Rht2) in the YHVWWZ $^{[6]}$, has significantly increased yield potential and yields obtained by farmers. However, planting densities of up to 750 plants per square meter are currently used to achieve high yield, particularly when reduced tillage is practiced. Lodging increased significantly at these densities, especially in high yielding environments where water and fertilizer are not limiting factors. Thus, the breeding objectives for the YHVWWZ include improvement in yield potential and lodging resistance under high planting densities. New cultivars must also carry resistance to major diseases such as powdery mildew, have excellent performances under both full and reduced irrigations, with acceptable processing quality for Chinese noodles and steamed bread.

Lodging usually occurs at the early grain-filling stage and its widespread occurrence in the YHVWWZ has four underlying factors: (1) frequent strong winds and rainstorms during the grain filling stage; (2) overuse of 
chemical fertilizers and high planting densities (400-750 plants per square meter) ${ }^{[7]}$; (3) broad adoption of flat planting and flood irrigation; and (4) lack of cultivars with lodging resistance under high input conditions ${ }^{[8]}$. Inadequate testing in breeding programs is partially responsible for the shortage of cultivars with increased lodging resistance because the moderate planting densities $(250$ plants per square meter) normally used in yield trials in breeding programs do not adequately represent current farm practices. However, effective selection for lodging resistance by breeders is mainly dependent upon the shorter and stiffer stems in the earlier segregating generations of semi-dwarf genotypes ${ }^{[6]}$, instead of targeting specific agronomic traits. Thus, it would be very useful to identify key selectable traits associated with lodging resistance under high planting densities.

Wheat lodging results from either failure of the anchorage system of the plant (root lodging), or bending or breakage at the basal stem internodes ${ }^{[9]}$. The problem of lodging increases with wind velocity and flood irrigation or intense rainstorms during the grain filling period. Such lodging occurs due to movement of the plant crown in the saturated surface soil, rather than bending or breakage of the stems ${ }^{[1]}$. Berry et al. ${ }^{[10]}$ reported that shoot and plant leverage were directly determined by the shoot height at its center of gravity, and the amplitude and frequency of movement (natural frequency) caused by wind gusts and the shoot number per plant. Both stem morphology and chemical characteristics of the lower stem are major determinants of stem strength ${ }^{[11-13]}$, whereas anchorage strength is affected by spread and depth of the root plate and strength of the surrounding soil ${ }^{[3,9]}$. The Rht dwarfing genes on homeologous group 4 chromosomes indirectly affect lodging-related traits through their pleiotropic effects $^{[14]}$. Additional lodging-related QTLs have been reported on chromosomes $2 \mathrm{D}$ and $6 \mathrm{BL}$ for stem stiffness ${ }^{[15]}, 1 \mathrm{~B}, 4 \mathrm{~B}, 4 \mathrm{D}, 6 \mathrm{D}$ and $7 \mathrm{D}$ for lodging and stem wall width $^{[14]}, 6 \mathrm{~B}, 7 \mathrm{~A}$ and $7 \mathrm{D}$ for stem carbohydrate content ${ }^{[16,17]}$, and 2D, 5A, 5D and 7D for root traits ${ }^{[14,18]}$. However, none of these genes has been used in breeding programs to improve lodging resistance.

Recently, lodging resistance has received more attention in international wheat program ${ }^{[3,19]}$, striving to raise yield potential to meet the challenge of the growing world population, climate change and declining natural resources. Attempts to increase grain yield mainly focus on optimizing dry matter partitioning to spikes, ensuring high and stable expression of harvest index, and minimizing structural dry matter requirements while maintaining lodging resistance. Rivera-Amodo et al. ${ }^{[20]}$ reported that selection for higher soluble dry matter in stems and/or lower structural dry matter could benefit enhanced grain partitioning under irrigated conditions. Maximizing lodging resistance in physiologically improved genotypes will require quantification of trade-offs among lodging- associated traits, dry matter partitioning indices and grain yield at different planting densities and in different environments $^{[3]}$. However, the dual requirements of breeding for higher yield and greater lodging resistance will still be very challenging ${ }^{[4]}$.

Although improving lodging resistance is an important objective in the YHVWWZ, little information is available on genotypic variation among current cultivars in lodging resistance under high planting densities. An improved understanding of lodging resistance among different cultivars and of factors associated with lodging-related traits is very important for development of future breeding strategies to further improve yields obtained by farmers. Thus, the objectives of this study were: (1) to characterize potential morphological traits related to lodging resistance under different planting densities, and (2) to investigate genetic variation in lodging resistance and lodging-related morphological traits. The information gained will be crucial for increasing yield potential and lodging resistance in China and other countries where improved yield and lodging resistance are primary objectives of breeding programs.

\section{Materials and methods}

\subsection{Plant materials and experimental design}

A field trial was conducted at the experiment station of Shandong Academy of Agricultural Science in Jinan (36.66 N, 117.07 E), Shandong province, in the 20082009 and 2009-2010 cropping seasons. The soil was a clay loam with mean contents of $156.7 \mathrm{mg} \cdot \mathrm{kg}^{-1}$ available $\mathrm{N}$, $24.6 \mathrm{mg} \cdot \mathrm{kg}^{-1}$ available $\mathrm{P}$, and $120.6 \mathrm{mg} \cdot \mathrm{kg}^{-1}$ available $\mathrm{K}$ at 0 to $20 \mathrm{~cm}$ upper soil layer. This region is classified as an irrigated wheat area with a humid climate, abundant solar resources and often hot and dry winds before maturity (Fig. 1a, Fig. 1b). Lodging events were recorded twice at the mid-grain filling stage (DC75 and DC80) $)^{[21]}$, while heavy rain and strong winds were recorded on May 16, 2009 (Fig. 1a) and May 21, 2010 (Fig. 1b).

Twenty-eight genotypes, including 24 released cultivars and 4 advanced lines, were selected from Shandong province representing the northern part of the YHVWWZ with a total area of around 8 million $\mathrm{hm}^{2}$, including the provinces of Shandong, Hebei, Shanxi, and northern parts of Jiangsu and Anhui (Table 1). They represent the most recent breeding progress and leading cultivars used by farmers, and also provide a range of variation in plant architecture and stem strength among current germplasm. All genotypes have similar plant height $(75-85 \mathrm{~cm})$, and are semi-dwarf with at least one dwarfing gene $(R h t-D 1 b)$; 11 genotypes have both $R h t-D 1 b$ and $R h t 8 c$. The genotypes were divided into two categories, resistant or susceptible to lodging, based on performance in farmers' 

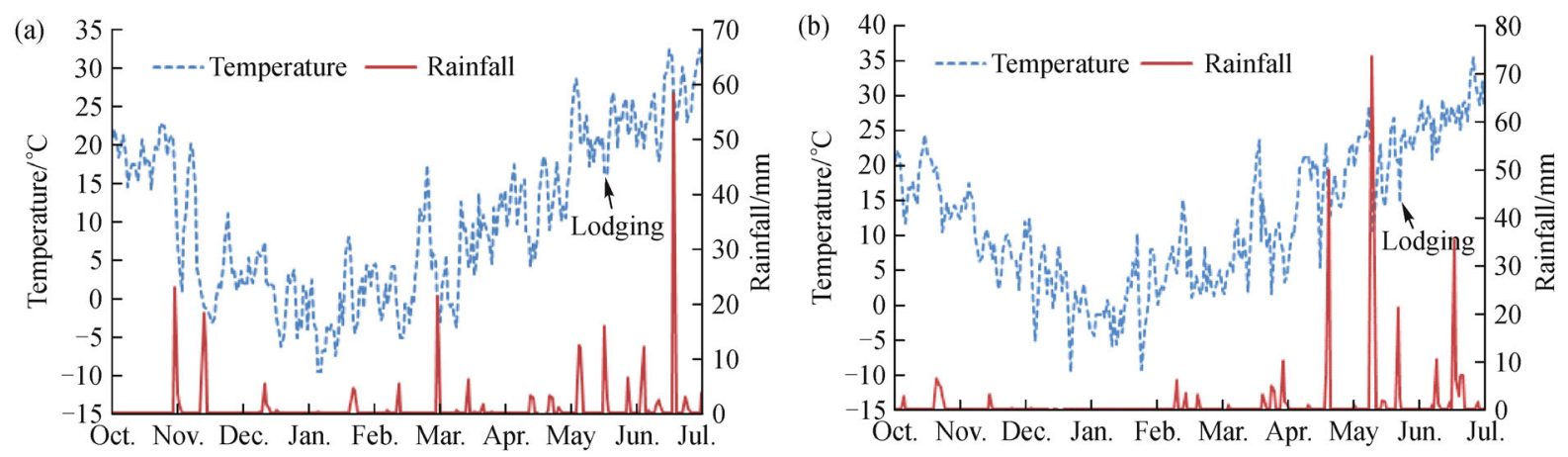

Fig. 1 Daily temperature and rainfall regimes during growing season at the experimental site in 2008-2009 (a) and 2009-2010 (b). Arrows indicate lodging events in the grain-filling stage.

Table 1 Pedigree, year released, dwarfing genes and lodging performance of 28 wheat genotypes grown at Jinan, Shandong, in the 2008-2009 and 2009-2010

\begin{tabular}{|c|c|c|c|c|}
\hline Genotype & Year released & Pedigree & Dwarfing gene & Lodging performance \\
\hline Lumai 21 & 1996 & $\mathrm{~F}_{4} \mathrm{~T}$ 144/Yumai 2 & Rht-D1b, Rht8c & 3 \\
\hline Lumai 23 & 1996 & Lumai 8/Dali'ai & Rht-D1b, Rht $8 c$ & 0 \\
\hline Jinan 17 & 1999 & Linfen 5064/Lumai 13 & Rht-Dlb & 1 \\
\hline Jimai 19 & 1999 & Linfen 5064/Lumai 13 & Rht-Dlb & 2 \\
\hline Jining 13 & 2000 & Yan 1934/84(4)046//Liao 83-1/2114 & $R h t-D 1 b$ & 0 \\
\hline Taishan 21 & 2000 & Lu 26744/Taishan 10//Lumai 7/3/Lumai 18 & $R h t-D 1 b$ & 1 \\
\hline Yannong 19 & 2001 & Yan 1934/Shan 82-29 & Rht-D1b & $3-4$ \\
\hline Zimai 12 & 2001 & Zi 917065/Zi 010292 & Rht-D1b & 0 \\
\hline Jimai 20 & 2003 & Lumai 14/Ji 884187 & Rht-D1b & 2 \\
\hline Weimai 8 & 2003 & $88-3149 /$ Aus 621108 & Rht-Dlb & 0 \\
\hline Yannong 23 & 2003 & Yan 1061/Lumai 14 & Rht-D1b & $1-2$ \\
\hline Jining 16 & 2004 & Yan 1934/84(4)046//Liao 83-1/2114 & Rht-Dlb & 0 \\
\hline Linmai 2 & 2004 & Lumai $23 /$ Lin $90-15$ & Rht-D1b, Rht8c & 0 \\
\hline Taishan 23 & 2004 & Tai $881414 /$ Tai 876161 & Rht-Dlb & 3 \\
\hline Yannong 24 & 2004 & Shan 229/Anmai 1 & Rht-Dlb & $1-2$ \\
\hline Taishan 24 & 2005 & Tai 904017/Zhengzhou 8329 & Rht-D1b & 1 \\
\hline Jimai 22 & 2006 & Ji 935024/Ji 935106 & $R h t-D 1 b, R h t 8 c$ & 0 \\
\hline Linmai 4 & 2006 & Lumai $23 /$ Lin $90-15$ & Rht-Dlb & 0 \\
\hline Shannong 15 & 2006 & Jinan 17/Jihe 916 & Rht-Dlb & 0 \\
\hline Wennong 6 & 2006 & Lu 915021//Lumai 18/Tai 876161 & Rht-D1b & 0 \\
\hline Liangxing 66 & 2008 & Ji 91102/Ji 935031 & $R h t-D 1 b, R h t 8 c$ & 0 \\
\hline Tainong 18 & 2008 & Laizhou 137/Yan 369-7 & Rht-D1b, Rht $8 c$ & 0 \\
\hline Taishan 223 & 2008 & Ji 5018/Lumai 21 & $R h t-D 1 b, R h t 8 c$ & 2 \\
\hline Zhongmai 155 & 2008 & Jimai 19/Lumai 21 & Rht-D1b, Rht $8 c$ & $1-2$ \\
\hline Ji 035037 & 2009 & Laizhou 95021/Yunfengzao 18 & $R h t-D 1 b, R h t 8 c$ & - \\
\hline Ji 046402 & 2009 & Ji 90(4)015/Han 5136 & $R h t-D 1 b, R h t 8 c$ & - \\
\hline Ji 065504 & 2009 & Annong 91168/Gaocheng 8901 & $R h t-D 1 b$ & - \\
\hline Ji 066324 & 2009 & Ji 965261/Yannong 19 & Rht-D1b, Rht8c & - \\
\hline
\end{tabular}

Note: Lodging performance was based on the reports from wheat breeders. Scores from 0 to 4 represent lodging scores from resistance to susceptible, scores above 3 were considered lodging sensitive. 
fields and breeding stations in Shandong province. A relatively large number of genotypes were included in the study to provide diversity in plant type and to insure that reliable information could be generated.

Two planting densities were used based on seeding rates recommended by agronomists (250 plants per square meter) and the high seeding rate (500 plants per square meter) used by farmers, respectively. Each treatment was arranged in a randomized complete block design with three replications. Each $1.2 \mathrm{~m}$ wide plot comprised $6 \mathrm{~m}$ rows and $4 \mathrm{~m}$ long with $0.2 \mathrm{~m}$ inter-row spacing. The trials were planted on Oct.18, 2008, and Oct. 16, 2009. Before planting, goat manure $\left(750 \mathrm{~kg} \cdot \mathrm{hm}^{-2}\right.$, providing about 4.9 $\mathrm{kg} \mathrm{N} \cdot \mathrm{hm}^{-2}, 3.5 \mathrm{~kg} \mathrm{P} \cdot \mathrm{hm}^{-2}$ and $1.7 \mathrm{~kg} \mathrm{~K} \cdot \mathrm{hm}^{-2}$ in the biomass) and $750 \mathrm{~kg} \cdot \mathrm{hm}^{-2}$ of a SACF (Sino-Arab Chemical Fertilizers Company Ltd., Qinhuangdao, Hebei Province) propriety fertilizer (providing about 120 $\mathrm{kg} \mathrm{N} \cdot \mathrm{hm}^{-2}, 120 \mathrm{~kg} \mathrm{P} \cdot \mathrm{hm}^{-2}$, and $60 \mathrm{~kg} \mathrm{~K} \cdot \mathrm{hm}^{-2}$ ) was incorporated into the soil by cultivation. An additional $150 \mathrm{~kg} \mathrm{~N} \cdot \mathrm{hm}^{-2}$ was applied at the first node stage (DC31) and followed by irrigation. This is a very high yielding irrigated environment with a wheat-soybean rotation; i.e., wheat is planted after harvesting soybean.

Irrigations, adjusted for rainfall, were provided at tillering (DC23, before winter), at stem elongation (DC31) and after anthesis (DC67-DC69) in both cropping seasons. The total amount of water applied was 2.25 to $2.70 \mathrm{ML} \cdot \mathrm{hm}^{-2}$. Fungicides (Triadimefon, Dupont Co. Ltd., Shanghai, at $0.2 \mathrm{~mL} \cdot \mathrm{L}^{-1}$ ) were used to control powdery mildew and yellow rust at spike emergence (DC59). Insecticides (Cyhalothrin, Nanjing Kingsun Bio-tech Co. Ltd., Nanjing, at $3.3 \mathrm{~mL} \cdot \mathrm{L}^{-1}$ and Imidacloprid, Karegreen Biotechnology Co. Ltd., Hangzhou, at $0.07 \mathrm{~mL} \cdot \mathrm{L}^{-1}$ ) were applied at $15 \mathrm{~d}$ intervals from heading to mid-grain filling to prevent aphid damage.

\subsection{Measurement of grain yield and lodging-related traits}

Lodging was assessed by measuring the angle of inclination of the stem base from the vertical and the lodged area of the whole plot with a score calculated following the method of Fischer and Stapper ${ }^{[1]}$, viz., lodging score $=$ percent of plot area lodged $\times$ angle of lodging from vertical position/90. Fifteen culms from a single row in each plot were used to measure pushing resistance from the center of gravity at DC73 with a prostrate tester (Fig. 2a, DIK-7401, Daiki Rika Kogyo Co. Ltd., Japan). Pushing resistance of the lower stem part at right angles to the row direction was measured when plants were forced to $45^{\circ}$ relative to the ground (Fig. 2b) ${ }^{[22]}$.

LAI at DC75 was calculated from incident and transmitted radiation measurements made at noon under sunny conditions utilizing the AccuPAR comptometer (Decagon Devices LP-80, Pullman, WA, USA). The extinction coefficient $(K)$ was measured by the AccuPAR, which depended on the zenith angle of the sun and the leaf angle distribution parameter (the typical value in wheat is $0.96)^{[23]}$.

Five main culms without roots were collected without damage to the stem. The center of gravity of each culm and length and diameter of the lower two internodes (internodes 1 and 2) ${ }^{[9]}$ were calculated. Ten culms of similar height were selected and uprooted from the middle rows of each plot at DC73. For each sample, the lower internodes were placed in a fan-driven dehydrator (AoCheng $881 \mathrm{DH}-$ 6 , Wujing, Jiangsu) and dried at $80^{\circ} \mathrm{C}$ for $48 \mathrm{~h}$. The dried samples were ground to pass through a $1 \mathrm{~mm}$ sieve in a planetary ball mill (Mitamura Riken Kogyo, Tokyo, Japan) and then used to extract water solute carbohydrates (WSC) using boiling deionized water. WSC concentrations were quantified by colorimetry using anthrone reagent ${ }^{[24]}$.

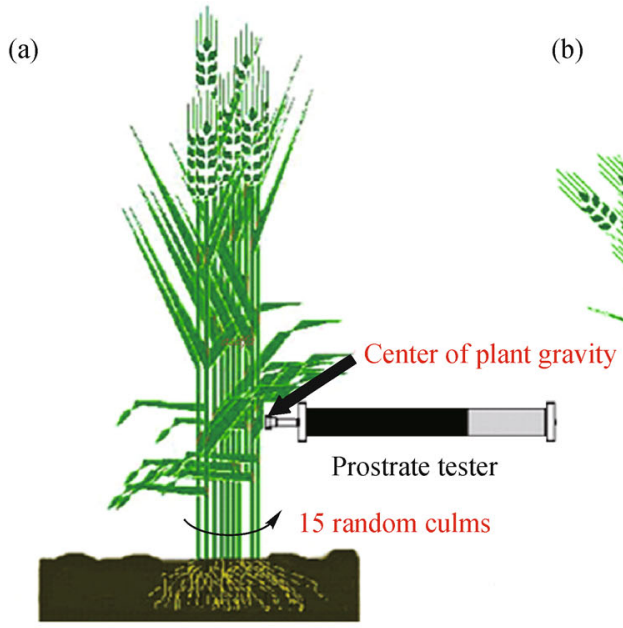

(b)

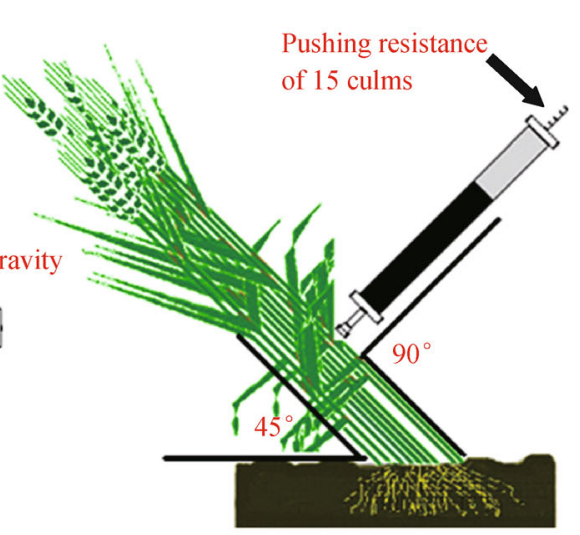

Fig. 2 Diagram illustrating the measurement of pushing resistance of 15 culms in the center of plant gravity. (a) Preparing for measuring pushing resistance; (b) the final state of the measurement of the pushing resistance. 
The dates of 50\% spike emergence (DC55), anthesis (DC65), and physiological maturity (DC93) were recorded, and plant height was measured from the soil surface to the tip of the spikes excluding the awns, based on the mean of three random points in the middle of the plot. After physiological maturity, two $0.5 \mathrm{~m}$ sectors of the central two rows, as subsamples, were harvested at soil level with scissors. The subsamples were weighed after drying for $48 \mathrm{~h}$ at $80^{\circ} \mathrm{C}$ and data for biomass, HI, spikes per square meter, grains per spike, grains per square meter, and thousand kernel weight (TKW) were recorded. Grain weight per spike $=$ grains per spike $\times \mathrm{TKW} / 1000$. After trimming $20 \mathrm{~cm}$ from the ends of each plot, the 4 central rows were hand harvested, threshed, dried and weighed to give a plot grain yield at $14 \%$ moisture. Final grain yield included the remaining plot grain yield, the grain weight of the subsample for biomass, and the grain weight of 10 tillers used for WSC determination.

\subsection{Statistical analyses}

Means and standard deviations (SD) were determined using PROC MEANS in the Statistical Analysis System $^{[25]}$. Analysis of variance (ANOVA) was performed using PROC MIXED for all traits, with cultivar as a fixed effect and years, planting density and replications nested in year effects as random effects. The significance of each source was determined by $F$-test. Least significant difference (LSD) tests were performed to determine significant differences between individual means. Phenotypic correlations were calculated using genotypic means for all measured stem characters, lodging score and pushing resistance. Principal component analysis (PCA) was performed on a correlation matrix made up of mean values for density, year and genotype.

\section{Results}

3.1 Growing-season conditions and variances of yield traits, lodging performance and morphological parameters

The growing-season rainfall was 279 and $362 \mathrm{~mm}$ in 2008-2009 and 2009-2010, respectively (Fig. 1). Both wheat growing-seasons were similar to an average year with annual rainfall of $300 \mathrm{~mm}$ and distributed mainly in grain-filling stage in late April, May and June. In 20082009 , a low temperature period suddenly occurred during the early tillering stage in mid-November and significantly effected on tillering growth. However, two spring freeze events (mean temperature $<-2^{\circ} \mathrm{C}$ ) around the jointing stage caused freezing damage to the crop (Fig. 1). Season 2009-2010 represented a normal year with steady temperature trends and a favorable temperature and rainfall throughout the grain-filling stage, and had higher grain weight and grain yield than season 2008-2009.
Grain yield was significantly affected by genotypes, years, planting densities and genotype $\times$ year interaction, but no significant effects by genotype $\times$ planting density and genotype $\times$ year $\times$ planting density interaction which was mainly due to the two growing-season conditions (Fig. 1) and the zero lodging in 12 genotypes under both planting densities (Table 2). The variation of lodging score was significant in genotypes, years, planting densities, and genotype $\times$ year, genotype $\times$ planting density and genotype $\times$ year $\times$ planting density interactions, which meant that all factors except annual trial repeat could effect plant lodging. It is worth noting that genotype (cultivar) was the predominant source of variation in grain yield, yield components, lodging-related traits, and morphological and physiological parameters (Table 2), while years and planting densities were also significant for some measured parameters. Furthermore, genetic variations in lodging score and grain yield at the low density were less than at the high density. Therefore, studying the effects of lodging-related traits and yield potential at high planting densities was more valuable at high planting densities.

\subsection{Effects of planting densities and genotypes on yield, lodging and related traits}

Lodging score at 250 plants per square meter increased by $136 \%$ compared to 500 plants per square meter (Table 3 ) although grain yield was only slightly increased from 7.6 to $7.8 \mathrm{t} \cdot \mathrm{hm}^{-2}$. Yield increase was largely associated with increased grain number per square meter from 15771 to 16309 , whereas TKW was slightly decreased from $41.5 \mathrm{~g}$ to $40.4 \mathrm{~g}$. Plant height and center of gravity increased when planting density increased, but the diameters of lower internodes were slightly decreased (Table 3 ). Finally, the lodging score increased since the stem strength was significantly reduced.

There were significant genetic variations in grain yield, $\mathrm{TKW}$, lodging score, pushing resistance, plant height, and diameters of first and second internodes among genotypes planted under both densities (Table 3). There were significant variations in major traits present among current cultivars and it would be possible to select these genotypes with high yield potential and lodging resistance at high planting densities.

Most of the cultivars in the study, except for the advanced lines Ji 046402, Ji 066324, Ji 065504 and Ji 035037, were released in the past 10 years, and have been adopted by farmers due to their high yield potential and broad adaptability. For example, Jimai 22 has been the leading cultivar in the YHVMMZ over the past 10 years, with a planting area of around 2 million ha per year in the last four years, and displays high yield potential, resistance to lodging, head frosting and powdery mildew, and outstanding performance under both full and reduced irrigation. Liangxing 66 is among the 10 most widely grown cultivars in northern China, with a planting area of 
Table 2 Summaries of analyses of variance for yield traits, morphological parameters and lodging performance in the 2008-2009 and 2009-2010 crop seasons

\begin{tabular}{|c|c|c|c|c|c|c|c|c|}
\hline Source & G & $\mathrm{Y}$ & $\mathrm{T}$ & $\mathrm{R}$ & $\mathrm{G} \times \mathrm{Y}$ & $\mathrm{G} \times \mathrm{T}$ & $\mathrm{G} \times \mathrm{Y} \times \mathrm{T}$ & Error \\
\hline$\overline{d f}$ & 27 & 1 & 1 & 2 & 27 & 27 & 28 & 222 \\
\hline $\mathrm{YLD} /\left(\mathrm{t} \cdot \mathrm{hm}^{-2}\right)$ & $43.3^{\mathrm{c}}$ & $1.7^{\mathrm{a}}$ & $3.3^{\mathrm{c}}$ & 1.2 & $27.4^{\mathrm{c}}$ & 5.8 & 10.7 & 57.5 \\
\hline TKW/g & $5552.5^{\mathrm{c}}$ & $407.5^{\mathrm{c}}$ & $91.9^{c}$ & 10.4 & $248.5^{\mathrm{a}}$ & $243.6^{\mathrm{a}}$ & 80.4 & 1137.6 \\
\hline SPSM & $1845544.3^{\mathrm{c}}$ & $6961531.4^{\mathrm{c}}$ & $164187.1^{\mathrm{c}}$ & 3504.8 & $349204.9^{\mathrm{c}}$ & 134903.3 & 134684.2 & 824933.5 \\
\hline GPS & $3482.5^{\mathrm{c}}$ & 12.6 & $970.7^{\mathrm{c}}$ & $1478.3^{\mathrm{c}}$ & 366.1 & 146.5 & 166.8 & 3833.5 \\
\hline $\operatorname{GPSM}\left(\times 10^{3}\right)$ & $1110.0^{\mathrm{c}}$ & $8967.9^{\mathrm{c}}$ & 0.5 & $244.4^{\mathrm{c}}$ & 314.7 & 282.3 & 202.9 & 1819.8 \\
\hline GWPS/g & $19.7^{\mathrm{c}}$ & $0.7^{\mathrm{c}}$ & $2.7^{\mathrm{c}}$ & $2.7^{\mathrm{c}}$ & 0.7 & 0.7 & 0.3 & 8.2 \\
\hline $\mathrm{LS} / \%$ & $6125.2^{\mathrm{c}}$ & $3138.8^{\mathrm{c}}$ & $1265.0^{\mathrm{c}}$ & 64.8 & $6125.2^{\mathrm{c}}$ & $2138.4^{\mathrm{c}}$ & $3403.4^{\mathrm{c}}$ & 3196.4 \\
\hline $\mathrm{PR} / \mathrm{N}(\mathrm{A}+15)$ & $2375.3^{\mathrm{c}}$ & $141.4^{\mathrm{c}}$ & $326.3^{\mathrm{c}}$ & 1.5 & $192.3^{\mathrm{a}}$ & $185.1^{\mathrm{a}}$ & 80.4 & 908.3 \\
\hline $\mathrm{BM} /\left(\mathrm{t} \cdot \mathrm{hm}^{-2}\right)$ & $474.1^{\mathrm{c}}$ & $376.8^{\mathrm{c}}$ & 5.5 & 0.3 & $773.7^{\mathrm{c}}$ & 101.1 & 105.4 & 694.5 \\
\hline HI & $0.1^{\mathrm{c}}$ & $0.04^{\mathrm{c}}$ & 0.0001 & 0.002 & $0.03^{\mathrm{c}}$ & 0.01 & $0.02^{\mathrm{b}}$ & 0.07 \\
\hline LAI & $97.2^{\mathrm{c}}$ & $75.7^{\mathrm{c}}$ & $1.6^{\mathrm{a}}$ & 2.1 & $19.8^{\mathrm{b}}$ & 12.4 & 9.2 & 77.6 \\
\hline $\mathrm{WSC} /\left(\mathrm{mg} \cdot \mathrm{g}^{-1}\right)$ & $155195.5^{\mathrm{c}}$ & $80475.3^{\mathrm{c}}$ & $16252.9^{\mathrm{c}}$ & 1743.6 & $42266.4^{\mathrm{c}}$ & 9712.9 & $56755.0^{\mathrm{c}}$ & 100634.7 \\
\hline $\mathrm{PH} / \mathrm{cm}$ & $2280.8^{\mathrm{c}}$ & $4973.1^{\mathrm{c}}$ & $221.3^{\mathrm{c}}$ & 19.1 & $263.8^{\mathrm{c}}$ & $179.8^{\mathrm{a}}$ & $213.6^{\mathrm{b}}$ & 872.6 \\
\hline $\mathrm{CG} / \mathrm{cm}$ & $688.4^{\mathrm{c}}$ & $4730.3^{c}$ & $108.6^{\mathrm{c}}$ & 7.9 & $150.6^{\mathrm{c}}$ & 35.2 & 45.9 & 402.8 \\
\hline $\mathrm{DFI} / \mathrm{mm}$ & $62.9^{\mathrm{c}}$ & $26.7^{\mathrm{c}}$ & $3.7^{\mathrm{c}}$ & 0.06 & $3.1^{\mathrm{c}}$ & 1.0 & $2.0^{\mathrm{a}}$ & 8.9 \\
\hline $\mathrm{DSI} / \mathrm{mm}$ & $81.4^{\mathrm{c}}$ & $8.7^{\mathrm{c}}$ & $4.8^{\mathrm{c}}$ & $0.4^{\mathrm{a}}$ & $2.7^{\mathrm{b}}$ & 1.1 & 1.5 & 11.1 \\
\hline $\mathrm{LFI} / \mathrm{cm}$ & $199.3^{\mathrm{c}}$ & $28.9^{\mathrm{c}}$ & 0.02 & 0.7 & 24.1 & $35.9^{\mathrm{a}}$ & 21.9 & 191.4 \\
\hline $\mathrm{LSI} / \mathrm{cm}$ & $441.3^{c}$ & $13.5^{\mathrm{c}}$ & $3.7^{\mathrm{c}}$ & 2.5 & 8.8 & $21.6^{\mathrm{b}}$ & 12.0 & 93.9 \\
\hline
\end{tabular}

Note: $\mathrm{G}$, genotype; $\mathrm{Y}$, year; $\mathrm{T}$, planting density; $\mathrm{R}$, replication; $\mathrm{G} \times \mathrm{Y}$, genotype $\times$ year variance; $\mathrm{G} \times \mathrm{T}$, genotype $\times$ planting density variance; $\mathrm{G} \times \mathrm{Y} \times \mathrm{T}$, genotype $\times$ year $\times$ planting density variance; YLD, grain yield; TKW, thousand kernel weight; SPSM, spikes per square meter; GPS, grains per spike; GPSM, grains per square meter; GWPS, grain weight per spike; LS, lodging score; PR, pushing resistance; BM, biomass; HI, harvest index; LAI, leaf area index; WSC, water solute carbohydrate; PH, plant height; CG, center of gravity; DFI, diameter of first internode; DSI, diameter of second internode; LFI, length of first internode; LSI, diameter of second internode. ${ }^{\mathrm{a}, \mathrm{b}, \mathrm{c}}$ Variance component is statistically different from zero at $P=0.05,0.01$ and 0.001 , respectively.

0.4 million $\mathrm{hm}^{2}$ per year. Taishan 21 and Taishan 23 had higher grain yields than other genotypes at higher density, but the lodging scores were significantly higher. Cultivars such as Jining 13, Jining 16, Linmai 4, Lumai 23, Tainong 18, Weimai 8, Wennong 6 and Zimai 12 showed good lodging resistance and increased grain yield under higher density, and had similar characters such as fewer tillers per plant, larger spikes and stronger stems (Table 3 ).

3.3 Important traits associated with lodging score and pushing resistance

A moderate correlation at 500 plants per square meter between lodging score and pushing resistance was observed $(R=-0.48, P<0.05$; Table 4$)$, indicating that pushing resistance was only a moderate and static indicator of lodging resistance under field conditions. Lodging score at high plant density was significantly and positively associated with LAI $(R=0.62, P<0.01)$ and center of gravity $(R=0.59, P<0.01)$, and negatively correlated with grain yield $(R=-0.53, P<0.01)$, TKW $(R=-0.48$, $P<0.05)$, grain weight per spike $(R=-0.45, P<0.05)$, and diameters of first $(R=-0.52, P<0.01)$ and second $(R=-0.49, P<0.01)$ internodes (Table 4).

Pushing resistance was significantly and positively correlated with TKW $(R=0.73, P<0.01)$, grains per spike $(R=0.71, P<0.01)$, grain weight per spike $(R=$ $0.89, P<0.01)$, biomass $(R=0.61, P<0.01)$, HI $(R=$ $0.41, P<0.05)$, and diameters of first $(R=0.71, P<0.01)$ and second $(R=0.77, P<0.01)$ internodes (Table 4). Furthermore, significant correlations were observed with spikes per square meter $(R=-0.82, P<0.01)$, grains per square meter $(R=-0.47, P<0.05)$, LAI $(R=-0.67$, $P<0.01)$ and length of first internode $(R=-0.65$, $P<0.01)$, indicating that reduced spikes per square meter, grains per square meter, LAI and diameter of first internode contribute to improvements in basal stem strength and pushing resistance.

3.4 Grouping of genotypes based on principal component analysis

At high plant density, PCA showed that grain yield was negatively correlated with plant height, center of gravity and lodging score (Fig. 3a). There was a positive and close relationship among grains per spike, grain weight per spike, TKW, biomass, pushing resistance and diameters of lower internodes, whereas grains per square meter and spikes per square meter had significant negative associations with the above traits. Furthermore, HI and water- 
Table 3 Wheat agronomic traits for 28 genotypes in the 2008-2009 and 2009-2010

\begin{tabular}{|c|c|c|c|c|c|c|c|c|c|c|c|c|c|}
\hline \multirow{2}{*}{ Source } & \multirow{2}{*}{$\mathrm{YLD}^{\mathrm{a}} /\left(\mathrm{t} \cdot \mathrm{hm}^{-2}\right)$} & \multirow{2}{*}{$\mathrm{TKW} / \mathrm{g}$} & \multirow{2}{*}{$\operatorname{GPSM}\left(\times 10^{3}\right)$} & \multirow{2}{*}{$\mathrm{PH} / \mathrm{cm}$} & \multirow{2}{*}{ LAI } & \multicolumn{2}{|c|}{$\mathrm{LS} / \%$} & \multicolumn{2}{|c|}{$\mathrm{PR} / \mathrm{N}$} & \multicolumn{2}{|c|}{$\mathrm{DFI} / \mathrm{mm}$} & \multicolumn{2}{|c|}{$\mathrm{DSI} / \mathrm{mm}$} \\
\hline & & & & & & $250^{\mathrm{b}}$ & $\overline{500}$ & 250 & 500 & 250 & 500 & 250 & 500 \\
\hline Lumai 21 & 7.3 & 36.8 & 17.5 & 82.6 & 5.8 & 1.1 & 17.2 & 2.7 & 1.4 & 4.0 & 3.6 & 4.3 & 4.1 \\
\hline Lumai 23 & 7.3 & 48.2 & 13.3 & 82.2 & 5.4 & 0.0 & 0.0 & 7.7 & 6.1 & 5.5 & 5.3 & 6.3 & 5.9 \\
\hline Jinan 17 & 7.6 & 38.4 & 16.2 & 78.4 & 6.1 & 1.7 & 6.3 & 1.1 & 0.8 & 3.4 & 3.2 & 3.8 & 3.5 \\
\hline Jimai 19 & 7.5 & 42.0 & 15.2 & 78.1 & 6.1 & 0.0 & 12.6 & 3.1 & 1.6 & 4.0 & 3.9 & 4.3 & 4.3 \\
\hline Jining 13 & 7.7 & 44.5 & 14.0 & 77.3 & 5.9 & 0.0 & 0.0 & 7.7 & 4.2 & 4.3 & 3.7 & 4.9 & 4.4 \\
\hline Taishan 21 & 8.2 & 39.6 & 16.3 & 77.5 & 5.6 & 0.0 & 4.3 & 3.0 & 1.0 & 3.7 & 3.6 & 3.9 & 3.9 \\
\hline Yannong 19 & 7.7 & 37.3 & 16.1 & 80.8 & 6.8 & 10.7 & 18.3 & 2.4 & 0.8 & 3.8 & 3.6 & 4.2 & 3.7 \\
\hline Zimai 12 & 7.8 & 45.0 & 14.6 & 77.3 & 5.3 & 0.0 & 0.0 & 6.8 & 3.9 & 4.7 & 4.6 & 5.2 & 5.0 \\
\hline Jimai 20 & 7.0 & 35.8 & 19.3 & 78.0 & 6.3 & 1.5 & 13.5 & 2.1 & 0.8 & 3.5 & 3.2 & 3.8 & 3.5 \\
\hline Weimai 8 & 7.5 & 49.7 & 14.0 & 82.4 & 4.9 & 0.0 & 0.0 & 12.0 & 8.1 & 4.5 & 4.1 & 4.9 & 4.7 \\
\hline Yannong 23 & 7.4 & 33.5 & 19.1 & 76.2 & 5.3 & 0.0 & 3.7 & 3.9 & 1.1 & 4.0 & 3.7 & 4.4 & 4.2 \\
\hline Jining 16 & 7.4 & 48.3 & 13.4 & 77.3 & 4.7 & 0.0 & 0.0 & 14.9 & 7.1 & 4.4 & 4.4 & 5.0 & 4.8 \\
\hline Linmai 2 & 8.5 & 39.9 & 16.7 & 75.4 & 6.0 & 0.0 & 0.6 & 3.1 & 2.1 & 4.0 & 3.7 & 4.4 & 4.3 \\
\hline Taishan 23 & 8.2 & 43.6 & 15.7 & 76.4 & 6.4 & 3.3 & 11.7 & 2.1 & 1.3 & 3.4 & 3.3 & 4.2 & 3.9 \\
\hline Yannong 24 & 7.8 & 39.2 & 17.9 & 79.8 & 5.7 & 0.0 & 0.9 & 4.0 & 1.3 & 4.1 & 3.9 & 4.4 & 4.2 \\
\hline Taishan 24 & 7.5 & 37.7 & 15.1 & 76.9 & 6.3 & 0.0 & 0.0 & 2.8 & 1.7 & 4.0 & 3.8 & 4.4 & 4.1 \\
\hline Jimai 22 & 8.1 & 41.8 & 17.1 & 74.9 & 5.9 & 0.0 & 0.0 & 4.0 & 2.3 & 4.4 & 4.2 & 4.5 & 4.4 \\
\hline Linmai 4 & 8.0 & 44.7 & 14.1 & 78.7 & 5.3 & 0.0 & 0.0 & 10.4 & 7.4 & 4.7 & 4.4 & 5.1 & 4.9 \\
\hline Shannong 15 & 7.9 & 45.1 & 14.1 & 75.6 & 5.9 & 0.0 & 0.0 & 1.6 & 1.2 & 4.0 & 3.7 & 4.3 & 4.1 \\
\hline Wennong 6 & 7.6 & 41.5 & 14.5 & 75.8 & 4.8 & 0.0 & 0.0 & 5.7 & 2.7 & 4.3 & 4.2 & 4.8 & 4.4 \\
\hline Liangxing 66 & 8.5 & 41.1 & 16.4 & 76.8 & 5.5 & 0.0 & 0.0 & 3.2 & 1.6 & 4.2 & 3.9 & 4.5 & 4.2 \\
\hline Tainong 18 & 7.7 & 40.0 & 16.5 & 70.9 & 4.8 & 0.0 & 0.0 & 5.8 & 3.8 & 4.6 & 4.4 & 4.9 & 4.7 \\
\hline Taishan 223 & 7.1 & 35.5 & 16.8 & 78.6 & 5.7 & 6.6 & 15.9 & 1.8 & 1.6 & 4.1 & 3.9 & 4.6 & 4.3 \\
\hline Zhongmai 155 & 7.8 & 36.3 & 18.0 & 79.1 & 5.5 & 0.0 & 1.1 & 3.3 & 1.3 & 4.2 & 4.0 & 4.4 & 4.2 \\
\hline Ji 035037 & 7.5 & 38.6 & 17.3 & 77.4 & 6.0 & 3.7 & 16.2 & 2.4 & 1.4 & 3.7 & 3.5 & 4.1 & 3.9 \\
\hline Ji 046402 & 8.1 & 41.7 & 15.5 & 73.9 & 6.3 & 0.0 & 1.1 & 4.2 & 1.6 & 3.9 & 3.7 & 4.5 & 4.2 \\
\hline Ji 065504 & 7.8 & 37.5 & 18.1 & 81.2 & 6.8 & 2.6 & 14.4 & 2.2 & 1.1 & 3.9 & 3.7 & 4.2 & 4.0 \\
\hline Ji 066324 & 7.8 & 43.2 & 16.2 & 75.3 & 5.7 & 0.0 & 2.0 & 2.1 & 1.8 & 3.8 & 3.7 & 4.2 & 4.0 \\
\hline Mean & 7.7 & 41.0 & 16.0 & 77.7 & 5.7 & 1.1 & 5.0 & 4.5 & 2.5 & 4.1 & 3.9 & 4.5 & 4.3 \\
\hline $\mathrm{CV} / \%$ & 7.4 & 11.8 & 37.6 & 6.7 & 16.3 & 4.8 & 11.2 & 2.7 & 2.2 & 0.4 & 0.4 & 0.3 & 0.4 \\
\hline
\end{tabular}

Note: YLD, mean grain yield; TKW, thousand kernel weight; GPSM, grains per square meter; PH, plant height; LAI, leaf area index; LS, lodging score; PR, pushing resistance; DFI, diameters of first; DSI, second internodes. ${ }^{\text {a }}$ Genotype means of YLD, TKW, GPSM, PH and LAI are from the average value of both $2008-2009$ and 2009-2010 crop seasons under both densities; ${ }^{2} 250$ and 500 indicates the plant densities at 250 and 500 plants per square meter, respectively.

soluble carbohydrates of the lower internodes showed a close relationship with grain yield (Fig. 3a).

Based on field performance and PCA analysis under high planting density, the 28 cultivars were divided into three types (Fig. 3b, Table 5): (I) moderate yield potential, but sensitive to higher planting density and lodging, e.g., Jimai 20, Lumai 21, Taishan 223; (II) moderate yield potential, tolerating higher planting density and lodging resistance, e.g., Jining 13, Jining 16, Linmai 4, Tainong 18; (III) high yield potential, tolerating higher plant density and lodging resistance, e.g., Jimai 22, Liangxing 66, and Limai 2. Type III cultivars had moderate stem traits and stem strength combined with outstanding lodging resistance and high grain yield (Table 5). Therefore, Type III genotypes will be more desirable both for breeding and production.

\section{Discussion}

\subsection{Trait responses to planting density}

Although increased planting density slightly increased spikes per square meter, grains per square meter, and grain 
Table 4 Pearson correlation coefficients $(R)$ of yield components, physiological and morphological traits with lodging score and pushing resistance based on average values of 500 plants per square meter from the 2008-2009 and 2009-2010 crop seasons

\begin{tabular}{|c|c|c|}
\hline Morphological character $(n=28)$ & Lodging score & Pushing resistance \\
\hline Lodging score/\% & 1.00 & $-0.48^{\mathrm{a}}$ \\
\hline Grain yield $/\left(\mathrm{t} \cdot \mathrm{hm}^{-2}\right)$ & $-0.53^{\mathrm{b}}$ & 0.12 \\
\hline Thousand kernel weight/g & $-0.48^{\mathrm{a}}$ & $0.73^{\mathrm{c}}$ \\
\hline Spikes per square meter & $0.42^{\mathrm{a}}$ & $-0.82^{\mathrm{c}}$ \\
\hline Grains per spike & -0.29 & $0.71^{\mathrm{c}}$ \\
\hline Grains per square meter & 0.35 & $-0.47^{\mathrm{a}}$ \\
\hline Grain weight per spike/g & $-0.45^{\mathrm{a}}$ & $0.89^{\mathrm{c}}$ \\
\hline Biomass $/\left(\mathrm{t} \cdot \mathrm{hm}^{-2}\right)$ & -0.13 & $0.61^{\mathrm{c}}$ \\
\hline Harvest index & -0.30 & $0.41^{\mathrm{a}}$ \\
\hline Leaf area index (DC75) & $0.62^{\mathrm{c}}$ & $-0.67^{\mathrm{c}}$ \\
\hline Carbohydrates content of stem $/\left(\mathrm{mg} \cdot \mathrm{g}^{-1}\right)$ & -0.36 & 0.31 \\
\hline Plant height $/ \mathrm{cm}$ & 0.25 & 0.25 \\
\hline Center of gravity $/ \mathrm{cm}$ & $0.59^{\mathrm{c}}$ & -0.32 \\
\hline Diameter of first internode/mm & $-0.52^{\mathrm{b}}$ & $0.71^{\mathrm{c}}$ \\
\hline Diameter of second internode $/ \mathrm{mm}$ & $-0.49^{\mathrm{b}}$ & $0.77^{\mathrm{c}}$ \\
\hline Length of first internode/cm & 0.26 & $-0.65^{\mathrm{c}}$ \\
\hline Length of second internode/cm & 0.08 & -0.06 \\
\hline
\end{tabular}

Note: ${ }^{\mathrm{a}, \mathrm{b}, \mathrm{c}}$ Variance component is statistically different from zero at $P=0.05,0.01$ and 0.001 , respectively.
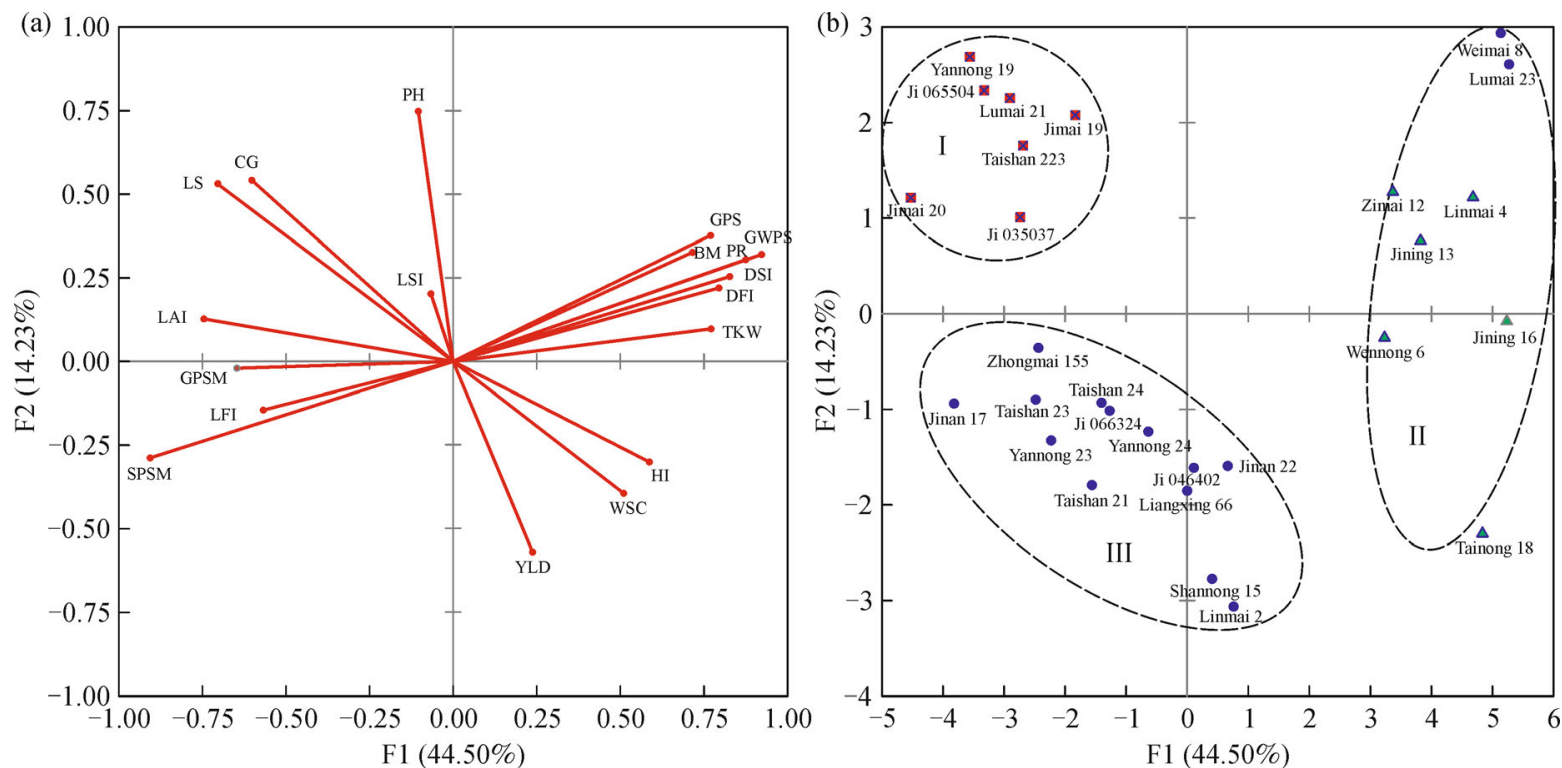

Fig. 3 Principal component analysis (PCA) of 18 parameters (a) for 28 genotypes (b) under high plant densities. YLD, grain yield; TKW, thousand kernel weight; SPSM, spikes per square meter; GPS, grains per spike; GPSM, grains per square meter; GWPS, grain weight per spike; LS, lodging score; PR, pushing resistance; BM, biomass; HI, harvest index; LAI, leaf area index; WSC, water solute carbohydrate; PH, plant height; CG, center of gravity; DFI, diameter of first internode; DSI, diameter of second internode; LFI, length of first internode; LSI, length of second internode.

yield, lodging score was significantly increased (Table 3 ). Higher plant density is usually accompanied by reduced kernel weight ${ }^{[7,26-28]}$, and decreased above ground bio- mass and HI. In particular, increased plant height, center of gravity and LAI intensifies the vibration amplitude of the plant population induced by wind and $\operatorname{rain}^{[11]}$, and 
Table 5 Phenotypic values based on average values of 500 plants per square meter in three types identified by principal component analysis

\begin{tabular}{|c|c|c|c|c|c|c|c|c|c|c|c|c|}
\hline Type & No. & $\mathrm{YLD} /\left(\mathrm{t} \cdot \mathrm{hm}^{-2}\right)$ & TKW/g & $\operatorname{GPSM}\left(\times 10^{3}\right)$ & $\mathrm{LS} / \%$ & $\mathrm{PR} / \mathrm{N}(\mathrm{A}+15)$ & LAI & $\mathrm{WSC} /\left(\mathrm{mg} \cdot \mathrm{g}^{-1}\right)$ & $\mathrm{PH} / \mathrm{cm}$ & $\mathrm{CG} / \mathrm{cm}$ & $\mathrm{DFI} / \mathrm{mm}$ & $\mathrm{DSI} / \mathrm{mm}$ \\
\hline $\bar{I}$ & 7 & $7.4 \mathrm{c}$ & $37.7 \mathrm{~b}$ & $17.2 \mathrm{a}$ & $9.6 \mathrm{a}$ & $1.8 \mathrm{c}$ & $6.2 a$ & $142.3 \mathrm{c}$ & $79.5 \mathrm{a}$ & $41.6 \mathrm{a}$ & $3.7 \mathrm{c}$ & $4.1 \mathrm{c}$ \\
\hline II & 8 & $7.6 \mathrm{~b}$ & $40.1 \mathrm{a}$ & $16.5 b$ & $0.0 \mathrm{c}$ & 7.1a & $5.2 \mathrm{c}$ & $165.8 \mathrm{a}$ & $77.7 \mathrm{~b}$ & $39.5 \mathrm{c}$ & $4.5 \mathrm{a}$ & $5.0 \mathrm{a}$ \\
\hline III & 13 & $7.9 \mathrm{a}$ & $45.2 \mathrm{~b}$ & $14.3 \mathrm{c}$ & $1.4 \mathrm{~b}$ & $2.2 \mathrm{~b}$ & $5.9 \mathrm{~b}$ & $151.5 \mathrm{~b}$ & $76.6 \mathrm{c}$ & $40.0 \mathrm{~b}$ & $3.8 \mathrm{~b}$ & $4.3 b$ \\
\hline
\end{tabular}

Note: I, moderate yield potential and lodging susceptible; II, moderate yield potential and lodging resistant; III, higher yield potential and lodging resistant. YLD, grain yield; TKW, thousand kernel weight; GPSM, grains per square meter; LS, lodging score; PR, pushing resistance; LAI, leaf area index; WSC, water solute carbohydrate; $\mathrm{PH}$, plant height; CG, Center of gravity; DFI, diameter of first internode; DSI, diameter of second internode. Means followed by the same letter within a column are not significantly different at $P=0.05$.

increases lodging as a consequence. This creates obstacles to harvesting and results in increased agronomic costs.

Stem traits and their composition positively contribute to lodging resistance ${ }^{[4,29]}$. Increasing planting density under abundant nitrogen levels promotes more tillers per unit area (spikes per square meter) and reduces radiation use efficiency (LAI) of lower leaves. The photosynthetic curtailment of WSC (Table 4) in the basal internodes reduces their strength. Basal internodes provide the leverage to hold plants upright, and are important in determining lodging resistance ${ }^{[9]}$. Stem diameter and thickness of lower internodes are significantly affected by planting density (Table 3$)^{[7]}$. Additionally, diameter and thickness of lower internodes are positively correlated ${ }^{[10]}$. The wall width of first internode is slightly thicker than the second. However, the first internode has almost twice the material strength as the second internode ${ }^{[29]}$. In the present study, the correlation between lodging score and diameter of first internode was only slightly but significantly greater than that of the second (Table 4), indicating that the first internode was more important for lodging resistance. Moreover, increased planting density may reduce stem WSC, which functions as the buffer of actual photosynthate in stems with direct effects on stem strength and grain filling ${ }^{[7,30,31]}$. Therefore, high planting density significantly decreased stem strength, WSC and even the resources required for grain filling ${ }^{[29]}$, thus leading to significantly increased lodging.

4.2 Plant pushing resistance, lodging performance and anchorage failure

Plant pushing resistance can be used to judge the strength of lower internodes, and its measurement can provide reasonably reliable data within $5 \mathrm{~min}$ per plot, and hence could be useful for selecting lodging-prone lines in breeding programs. In general, pushing resistance statically showed the anchorage force of stem movement, but it was difficult to separate rankings for stem and root lodging ${ }^{[9,32]}$. However, the pushing resistance test could not be used to replicate wind-induced lower internode bending, so it was difficult to demonstrate anchorage failure. In the present study, pushing resistance had a moderate relationship with lodging score (Table 4), largely due to two reasons: (1) it is a static test without the ability to simulate the natural frequency, and (2) tests are performed on dry soil rather than wet soil. Berry et al. ${ }^{[11]}$ also reported that the precision of predicted lodging through specially developed instruments would be close to the best natural performance expected by using static loads.

Anchorage failure was interactively affected by soil structure, plant root characters, stem natural frequency and lower stem strength ${ }^{[10]}$, and a weakening of any of these could contribute to lodging sensitivity. Current cultivars in the YHVWWZ are characterized by more tillers, close plant architecture and semi-erect flag leaves, and these characters could benefit increasing light interception, above-ground biomass, and grain yield ${ }^{[6]}$, but could cause reduction in root: shoot $\mathrm{ratio}^{[33]}$. Consequently, root plate spread has been trending downward in modern cultivars $^{[33]}$, which indicates that anchorage strength could be reduced concomitantly with the decrease of root plate spread $^{[10,29]}$. We observed differences between lodging resistant and susceptible genotypes in the field, however the root distribution characteristics of 28 genotypes were not measured. Compared to the lodging resistant genotype Jimai 22, the susceptible genotypes Yannong 19 and Taishan 23 with more shoots and abundant above-ground biomass had narrower crown root systems, characteristics that usually allow a greater vibrational range and frequency under high wind conditions, leading to anchorage failure in wet and soft soils. As discussed above, anchorage strength and root traits were also valuable traits for understanding lodging resistance, thus it is highly recommended that both stem and lodging traits needed to be considered for characterization of genotypes in lodging resistance.

\subsection{Effect of genotype on lodging-related traits}

Genotype is important in determining yield potential and degree of lodging resistance (Table 2$)^{[1,4,29]}$. For example, Liangxing 66 showed resistance to lodging and produced grain yields of more than $8 \mathrm{t} \cdot \mathrm{hm}^{-2}$ under both planting densities. Taishan 21 and Taishan 23 had similar yields at both planting densities, but were susceptible to lodging (Table 3). Consistent with the report of Tripathi et al. ${ }^{[29]}$, lodging resistance was significantly and positively correlated with spikes per square meter; in fact, this parameter explained $79 \%$ of the variation in lodging score. Six cultivars with the highest spikes per square meter at both planting densities over the two years, viz. Ji 066324, Jinan 
17, Jimai 20, Taishan 23, Yannong 23 and Zhongmai 155, were susceptible to lodging and did not produce the highest grain yields (Table 3). Genotypes such as Jimai 22, Liangxing 66, Linmai 2, Shandong 15, Taishan 24 and Yannong 24 with higher grain yield and better lodging resistance at both planting densities generally had modest spikes per square meter (Table 3 ). Therefore, in achieving a lodging-proof ideotype for breeding programs, genotypes with the most tillers per unit area could have an increased risk of lodging, and might not be recommended as parents for plant breeding ${ }^{[4]}$.

Stem diameter and its physiological components in the lower internodes explained $49 \%-65 \%$ of the variation in lodging score ${ }^{[29]}$, and were therefore identified as important parameters for improving lodging resistance (Table 4). Although greater diameter of lower internodes was positively correlated with lodging resistance, increased lower stem diameter can reduce tillers per unit area and grain yield ${ }^{[34]}$, thus the relationship between stem structure and grain yield needs to be appropriately considered in breeding programs. However, differences in the diameters of lower internodes contributed very little to differences between lodging resistant and susceptible genotypes in the present study (Table 5). Berry et al. ${ }^{[11]}$ also reported that a slight strengthening of the stem base and anchorage system would lead to large reductions in lodging risk. Eight genotypes with superior lodging resistance and moderate yield potential in our study had wider lower internodes (more than $4.3 \mathrm{~mm}$ ), whereas other genotypes with good lodging performance and greater yield potential had only moderate diameters ranging from 3.7 to $3.9 \mathrm{~mm}$. Since significant genetic variation was observed in the diameters of lower internodes among the tested cultivars (Table 5), it is feasible that increases in lower internode diameter (for example, a target diameter $4.0 \mathrm{~mm}$ ) could be achieved by breeding and would be likely to improve the level of lodging resistance.

\section{Conclusions}

Higher planting density was accompanied by slight increases in grain yield, but with a significantly increased lodging risk. A planting density of 500 plants per square meter could be used to select genotypes with high yield potential and lodging resistance in optimum environments. Plant height, center of gravity, LAI and diameter of lower internodes were the major traits associated with lodging resistance under high planting density. Pushing resistance was significantly associated with the diameter of the lower stem, and could be used to identify genotypes with high stem strength in order to improve lodging resistance. Significant genotypic variation under high planting density is available for improving grain yield, lodging resistance, and physiological and morphological traits. Liangxing 66,
Jimai 22, Linmai 2, and Shannong 15 are recommended as outstanding cultivars for production and for use as elite parents in breeding programs under high planting densities.

Acknowledgements The authors are grateful for the critical review of this manuscript by Prof. R.A. McIntosh, Plant Breeding Institute, University of Sydney. This study was supported by the National Natural Science Foundation of China (31161140346), the State Key Laboratory of Crop Biology (2014KF02), and the State Key Laboratory of Crop Stress Biology in Arid Areas.

Compliance with ethics guidelines Yonggui Xiao, Jianjun Liu, Haosheng $\mathrm{Li}$, Xinyou Cao, Xianchun Xia, and Zhonghu He declare that they have no conflict of interest or financial conflicts to disclose.

This article does not contain any studies with human or animal subjects performed by any of the authors.

\section{References}

1. Fischer R A, Stapper M. Lodging effects on high-yielding crops of irrigated semidwarf wheat. Field Crops Research, 1987, 17(3-4): 245-258

2. Pumphrey F V, Rubenthaler G L. Lodging effects on yield and quality of soft white wheat. Cereal Chemistry, 1983, 60(4): 268-270

3. Foulkes M J, Slafer G A, Davies W J, Berry P M, Sylvester-Bradley R, Martre P, Calderini D F, Griffiths S, Reynolds M P. Raising yield potential of wheat. III. Optimizing partitioning to grain while maintaining lodging resistance. Journal of Experimental Botany, 2011, 62(2): 469-486

4. Berry P M, Sylvester-Bradley R, Berry S. Ideotype design for lodging-resistant wheat. Euphytica, 2007, 154(1-2): 165-179

5. He Z H, Xia X C, Peng S B, Thomas A L. Meeting demands for increased cereal production in China. Journal of Cereal Science, 2014, 59(3): 235-244

6. Xiao Y G, Qian Z G, Wu K, Liu J J, Xia X C, Ji W Q, He Z H. Genetic gains in grain yield and physiological traits of winter wheat in Shandong Province, China, from 1969 to 2006. Crop Science, 2012, 52(1): 44-56

7. Wang C Y, Dai X L, Shi Y H, Wang Z L, Chen X G, He M R. Effects of nitrogen application rate and plant density on lodging resistance in winter wheat. Acta Agronomica Sinica, 2012, 38(1): 121-128 (in Chinese)

8. Liu X, Ju X, Zhang F, Pan J, Christie P. Nitrogen dynamics and budgets in a winter wheat-maize cropping system in the North China Plain. Field Crops Research, 2003, 83(2): 111-124

9. Berry P M, Spink J H, Gay A P, Craigon J. A comparison of root and stem lodging risks among winter wheat cultivars. Journal of Agricultural Science, 2003, 141(2): 191-202

10. Berry P M, Griffin J M, Sylvester-Bradley R, Scott R K, Spink J H, Baker C J, Clare R W. Controlling plant form through husbandry to minimize lodging in wheat. Field Crops Research, 2000, 67(1): 5981

11. Berry P M, Sterling M, Baker C J, Spink J, Sparkes D L. A calibrated model of wheat lodging compared with field measurements. Agricultural and Forest Meteorology, 2003, 119(3-4): 167- 
180

12. Tripathi S C, Sayre K D, Kaul J N. Planting systems on lodging behavior, yield components, and yield of irrigated spring bread wheat. Crop Science, 2005, 45(4): 1448-1455

13. Kong E Y, Liu D C, Guo X L, Yang W L, Sun J Z, Li X, Zhan K H, Cui D G, Lin J X, Zhang A M. Anatomical and chemical characteristics associated with lodging resistance in wheat. Crop Journal, 2013, 1(1): 43-49

14. Verma V, Worland A J, Sayers E J, Fish L, Caligari P D S, Snape J W. Identification and characterization of quantitative trait loci related to lodging resistance and associated traits in bread wheat. Plant Breeding, 2005, 124(3): 234-241

15. Keller M, Karutz Ch, Schmid J E, Stamp P, Winzeler M, Keller B, Messmer M M. Quantitative trait loci for lodging resistance in a segregating wheat $\times$ spelt population. Theoretical and Applied Genetics, 1999, 98(6-7): 1171-1182

16. Rebetzke G J, van Herwaarden A F, Jenkins C, Weiss M, Lewis D, Ruuska S, Tabe L, Fettell N A, Richards R A. Quantitative trait loci for water-soluble carbohydrates and associations with agronomic traits in wheat. Australian Journal of Agricultural Research, 2008, 59(10): 891-905

17. McIntyre C L, Casu R E, Rattey A, Dreccer M F, Kam J W, van Herwaarden A F, Shorter R, Xue G P. Linked gene networks involved in nitrogen and carbon metabolism and levels of watersoluble carbohydrate accumulation in wheat stems. Functional \& Integrative Genomics, 2011, 11(4): 585-597

18. Hamada A, Nitta M, Nasuda S, Kato K, Fujita M, Matsunaka H, Okumoto Y. Novel QTLs for growth angle of seminal roots in wheat (Triticum aestivum L.). Plant and Soil, 2012, 354(1-2): 395-405

19. Reynolds M, Bonnett D, Chapman S C, Furbank R T, Manès Y, Mather D E, Parry M A J. Raising yield potential of wheat. I. Overview of a consortium approach and breeding strategies. Journal of Experimental Botany, 2011, 62(2): 439-452

20. Rivera-Amado C, Trujillo-Negrellos E, Reynolds M, SylvesterBradley R, Molero G, Foulkes J. Genetic variation in total, soluble and structural DM partitioning among plant organs and association with harvest index in elite spring wheat lines. In: Reynolds M, Molero G, Quilligan E, Listman M, Braun H, eds. Proceedings of the 4th International Workshop of the Wheat Yield Consortium, Sonora: CIMMYT, 2014, 35-72

21. Zadoks J C, Chang T T, Konzak C F. A decimal code for growth stages of cereals. Weed Research, 1974, 14(6): 415-421
22. Xiao S H, Zhang X Y, Yan C S, Zhang W X, Hai L, Guo H J. Determination of resistance to lodging by stem strength in wheat. Scientia Agricultura Sinica, 2002, 35(1): 7-11 (in Chinese)

23. AccuPAR. Accupar-80 user's manual, v3.4. Decagon Devices, Inc., Pullman, WA., 2001

24. Xue G P, McIntyre C L, Rattey A R, van Herwaarden A F, Shorter R. Use of dry matter content as a rapid and low-cost estimate for ranking genotypic differences in water-soluble carbohydrate concentrations in the stem and leaf sheath of Triticum aestivum. Crop and Pasture Science, 2009, 60(1): 51-59

25. SAS Institute. SAS user's guide: statistics. SAS Inst., Cary, NC, 2000

26. Spink J H, Semere T, Sparkes D L, Whaley J M, Foulkes M J, Clare $\mathrm{R}$ W, Scott R K. Effect of sowing date on the optimum plant density of winter wheat. Annals of Applied Biology, 2000, 137(2): 179-188

27. Tripathi S C, Sayre K D, Kaul J N, Narang R S. Lodging behavior and yield potential of spring wheat (Triticum aestivum L.): effects of ethephon and genotypes. Field Crops Research, 2004, 87(2-3): 207-220

28. Bassu S, Asseng S, Giunta F, Motzo R. Optimizing triticale sowing densities across the Mediterranean basin. Field Crops Research, 2013, 144(20): 167-178

29. Tripathi S C, Sayre K D, Kaul J N, Narang R S. Growth and morphology of spring wheat (Triticum aestivum L.) culms and their association with lodging: effects of genotypes, $\mathrm{N}$ levels and ethephon. Field Crops Research, 2003, 84(3): 271-290

30. Knapp J S, Harms C L, Volenec J J. Growth regulator effects on wheat culm nonstructural and structural carbohydrates and lignin. Crop Science, 1987, 27(6): 1201-1205

31. Acreche M M, Slafer G A. Lodging yield penalties as affected by breeding in Mediterranean wheats. Field Crops Research, 2011, 122 (1): $40-48$

32. Niu L Y, Feng S W, Ru Z G, Li G, Zhang Z P, Wang Z W. Rapid determination of single-stalk and population lodging resistance strengths and an assessment of the stem lodging wind speeds for winter wheat. Field Crops Research, 2012, 139: 1-8

33. Siddique K H M, Belford R K, Tennant D. Root: shoot ratios of old and modern, tall and semi-dwarf wheats in a Mediterranean environment. Plant and Soil, 1990, 121(1): 89-98

34. Kelbert A J, Spaner D, Briggs K G, King J R. Screening for lodging resistance in spring wheat breeding programmes. Plant Breeding, 2004, 123(4): 349-354 